\title{
A CLINICAL CASE OF AN 'ALLEGED ASSAULT' : ARE THEY FABRICATED INJURIES?
}

\author{
W.R.A.S. Rajapaksha, *P.Paranitharan, **W.N.S. Perera \\ Post Graduate trainee, *Senior Lecturer, **Head \\ Department of Forensic Medicine, Faculty of Medicine, Ragama \\ Sri Lanka
}

\section{Introduction}

Self inflicted injuries which are usually non fatal may be motivated by some form of gain. The fabrication of injuries to simulate an assault is seen among the self inflicted injuries. In such cases with the difficulties that sometimes arise in determining whether injuries are self inflicted or not, the finding of symmetrical ómirror image injuriesô provides compelling evidence of self mutilation unless a plausible alternative explanation is available.(1) We report a case of fabricated injuries where the victim tried to implicate a group of individuals alleging assault.

\section{Case report}

A 23 year old right handed painter gave a history of ábductionô and ássaultô by a group of 6 unknown people while he was traveling in a motor bicycle. While in their custody he was punched, slapped and several cuts and scrapes were made with a knife used by them. He was kept in detention for about 3 hours and later dumped in an isolated area. On the same day he was admitted to a tertiary care hospital. He was under duress with the wedding arrangements in the near future. There was no history of psychiatric disorder or addiction to drugs and alcohol.

Medico $\ddot{i}$ Legal examination revealed multiple, parallel, over lapping, obliquely placed linear superficial abraded injuries.

on right cheek over an area of $14 \mathrm{~cm} \mathrm{x} 3$ $\mathrm{cm}$.(Figure 1) Similar type of injuries were present on the left cheek but less prominent. (Figure 2) There were 3 parallel linear superficial cuts with surrounding red flush on the anterior aspect of left upper chest. Multiple comparable superficial cut injuries were seen on the flexor aspect of left forearm and right forearm. (Figure 3, 4) The left arm mostly on the lateral aspect showed multiple superficial cut injuries. (Figure 5)There were no other injuries or scars found on the body which included the posterior aspect of the body. (Figure 6) The injuries were examined almost 27 hours after the infliction and the appearance of them were compatible with the time interval. The details of the clothing worn at the time of incident were not available. 


\section{Legends}

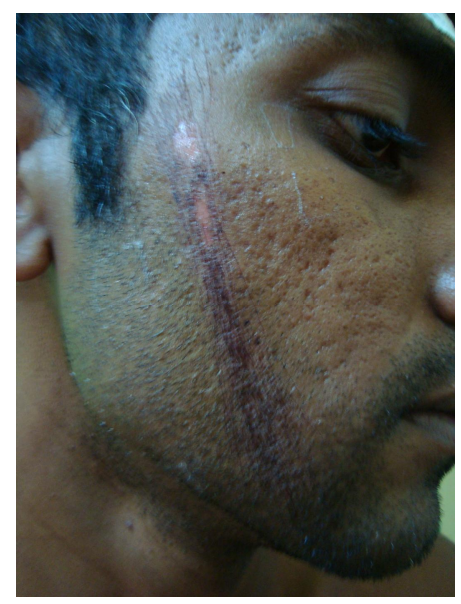

Figure 1 - Right cheek showing Multiple superficial, parallel obliquely placed abraded injuries

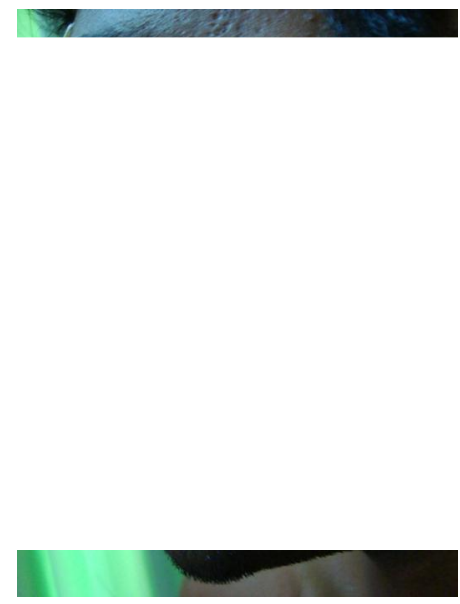

Figure 2 - Left cheek showing superficial, obliquely placed abraded injuries

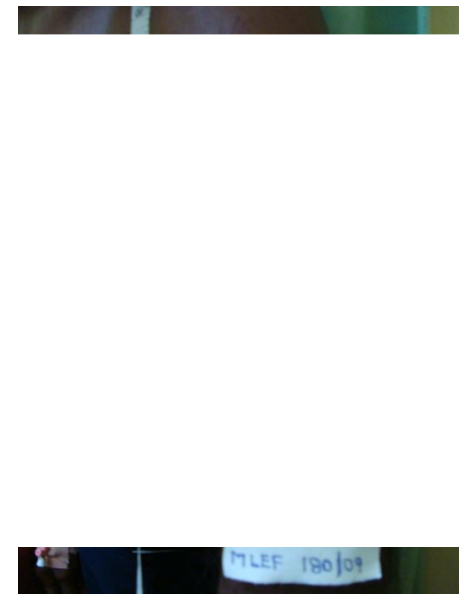

Figure 3 - Left arm with multiple superficial cuts

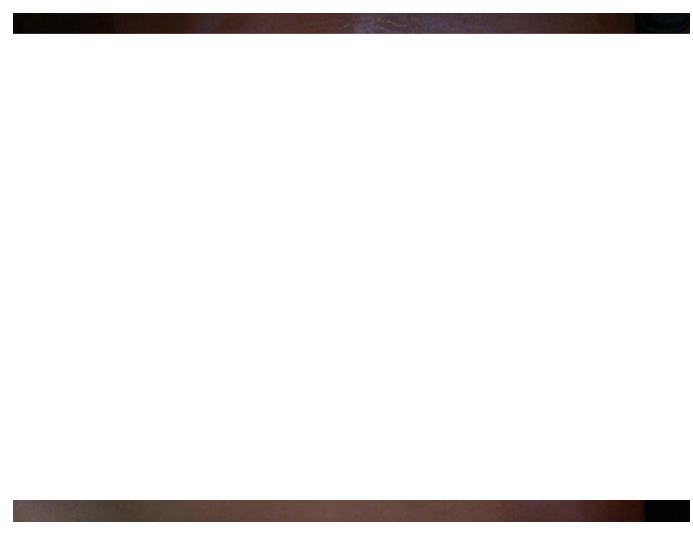

Figure 4 - Left forearm with multiple, linear, superficial cut injuries

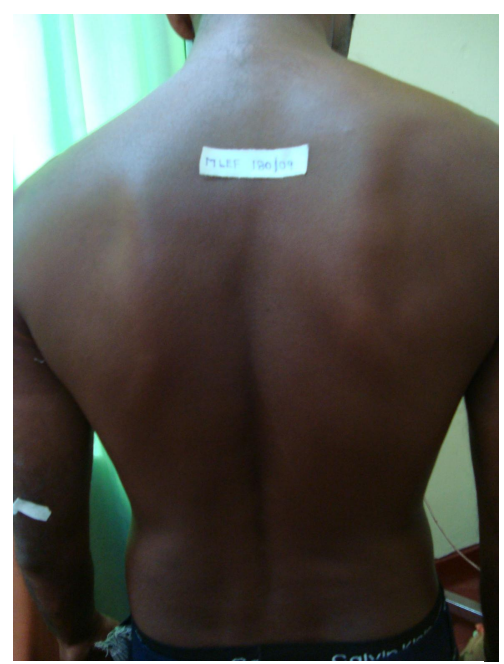

Figure 6 - back of the body devoid of any injuries

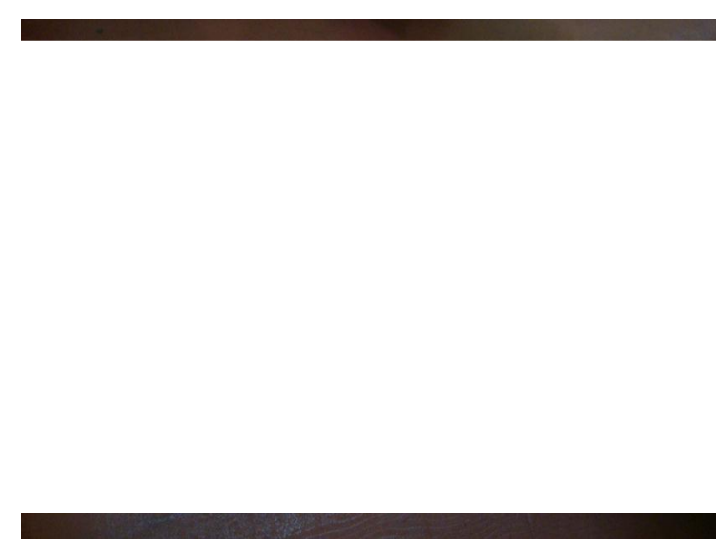

Figure 5 - Right forearm with linear superficial cut injuries

\section{Discussion}

Self infliction of injuries among males is seen in Sri Lanka especially among drug addicts, detainees and mental patients. Self inflicted injuries, usually non fatal, may be motivated by some form of gain. The most common is fabrication of an injury to simulate an assault. (2) The underlying motives for fabricated injuries vary from arousal of sympathy to that of hate. There are several etiological theories for self harm behaviour such as past trauma, invalidation, sexual and physical abuse, neglect and neurochemical changes. (3)In this case the victim never gave a history of self infliction 
of injuries or motivation to do so. Though he gave a history of kicking and slapping by 6 people there were no injuries on the body similar to imprint slap marks or contusions caused by the shod foot. The injuries which were present were superficial and involving the accessible parts of the body. There was symmetrical involvement of both cheeks and fore arms. The most common type of injuries was superficial cuts. The injuries on the cheeks appeared like superficial abrasions. According to the history given by the victim the weapon involved is a penknife. The mechanism of causation of abrasions by a penknife could be due to a lesser force or the abrasions were actually very superficial cuts. The fingernails of the victim were trimmed at the time of examination. The inaccessible parts of the body especially the back was free of any injuries.

When ever there is no history of self infliction but there is an allegation of assault and if the forensic pathologist had reasons to believe that it was self inflicted to fabricate injuries, then he had to decide on the circumstances based on the injury pattern. In this case the injuries were mostly on the left side corresponding to the right hand usage of the victim and avoiding sensitive areas. $(2,3)$ Further the superficial abrasions on both cheeks and superficial cuts in forearms appear as closer to identical images in their superficiality involving the skin, position of an oblique placement and type of injuries as superficial cuts and abrasions.(1)All the injuries were present only over in accessible parts of the body. Even though the mechanism of infliction is most likely due to self infliction the motive behind is to allege a group of individuals of assault and thus resulting in fabrication of injuries. Literature survey revealed similar cases of fabricated injuries where the motive was to mimic violence and simulation of an assault. In one instance an individual had even tried to inflict gunshot injuries to fabricate violence. (4), (5), (6). There was another case where the victim had tried to self strangulate to fabricate injuries. He initially claimed that he was gagged, tied and robbed. But later he admitted that he had fabricated the injuries. (7)Though the fabricated injuries are common phenomenon of self inflicted injuries, the symmetrical involvement of body parts especially the cheeks are less common. In comparison to the self inflicted injuries for suicidal purposes the fabricated injuries in the face are very superficial avoiding sensitive areas like eyes, nose, lips and ears. (2)

Given the difficulties that arise in determining whether these injuries are self inflicted or not, the findings of typical characteristics of self-infliction as described above and the absence of defense injuries in the palmer aspects of hand further supports the conclusion of fabricated injuries. (8), (9), (2)

\section{Acknowledgement}

The authors wish to extend their sincere gratititude to Dr L.B.L de Alwis for his effort in going through this paper and the valuable guidance given to publish this case report. 


\section{References}

1. Byard RW, Gibert JD, Tsokos M.Symmetrical ñmirror- image injuriesò and the ñchess boardò pattern: useful markers of self mutilation. American Journal of Forensic Medicine and Pathology.2007 Sep;28(3):255-8

2. Saukko P, Knight B. Self- inflicted injury. In: Forensic Pathology. $3^{\text {rd }}$ ed.London: Arnold; 2004:235-244.

3. Karger B, Duchesne A, Ortmann C, Brinkmann B. Unusual self inflicted injuries simulating a criminal offence. International Journal of Legal Medicine.1997;110(5):26772 .

4. Fracasso T, Lobrer L, Karger B. Self inflicted gun shot injury simulating a criminal offence. Forensic Science International.2009.Jul 1; 188(1-3).

5. Nadjem H, Pollak S.Simulation of an assault with self-tying and vaginal insertion of metal objects. Forensic Science International 2008.177(2):29-33.
6. Faller ï Marquardt M, Ropohl D, Pollak S. Excoriations and contusions of the skin as artefacts in fictitious sexual offences. Journal of Clinical Forensic Medicine.1995;2(3):129-135.

7. Andrea L, Klaus P, Sven A.Extensive petechiae in attempted selfstrangulation.Journal of Forensic Sciences.2009;54(1):212-215.

8. M.Faller- Marquardt, S.Pollak.Self inflicted injuries with negative political overtones. Forensic Science International .2006;159(2):226-229.

9. Schmidt U, Faller- Marquardt M, Tatschner T, Walter K, Pollak S. Cuts to the offenderôs own hand- unintentional self infliction in the course of knife attacks. International Journal of Legal Medicine;2004.118(6):348354 